\title{
A História da Patologia no INCA
}

\author{
History of the Pathology Department at INCA
}

Lucilia Zardo, ${ }^{1}$ Francisco Fialho²e Darcy da Silva Guimarães ${ }^{\dagger}$

${ }^{1}$ Chefe Interina da Divisão de Patologia do Instituto Nacional de Câncer (INCA).

${ }^{2}$ Ex-Chefe do Serviço de Anatomia Patológica e Ex-Diretor do INCA

${ }^{\dagger}$ Assessor do Gabinete da Direção Geral do IN CA. Falecido em dezembro de 2002.

Em 1938, após a criação do "Centro de Cancerologia", através do D ecreto Lei no 378 , de 13 de janeiro de 1937, o Laboratório de Anatomia Patológica considerado oficial, era o da antiga Saúde Pública, chefiado pelo seu fundador, Professor Amadeu Fialho. Assim permaneceu até 0 final do ano de 1946, quando, então, o Serviço N acional de Câncer e o Instituto de Câncer instalaram-se, ainda que provisoriamente, no H ospital G affrée e Guinle.

$\mathrm{O}$ que o Instituto $\mathrm{N}$ acional de $\mathrm{C}$ âncer deve ao antigo Laboratório de Saúde Pública é incalculável. Foi ele, pela sempre zelosa colaboração do Professor Fialho, uma das peças mais importantes nas atividades do "Centro de Cancerologia". Colaborou, por demais, na capacitação técnica do Instituto, permitindo que funcionasse em corretas bases científicas, além de auxiliar decisivamente no aprimoramento e no desenvolvimento de grupos de profissionais que se iniciavam na área da Cancerologia.

Em dezembro de 1946, já tendo como principal responsável o Professor Francisco Fialho, o Laboratório de Anatomia Patológica do Instituto de $C$ âncer foi instalado e equipado no $\mathrm{H}$ ospital G raffrée e Guinle. O cupava, precisamente, metade do andar térreo do prédio dos Laboratórios daquele H ospital. D esde o princípio, funcionou dentro de corretos princípios da anatomia patológica, constituindo-se dos setores da técnica histológica, da autópsia, de documentação e de arquivos. É desse modo que se explica o seu patrimônio atual.

Em 1957, com a transferência do Instituto deC âncer para o prédio localizado na Praça C ruz Vermelha $n=23$, o Laboratório de Anatomia Patológica ocupou parte do 3o andar. Em 1964, com a inauguração do prédio anexo, esse L aboratório passou a funcionar em todo 0 50 andar, o que permitiu triplicar as suas atividades. Até esta data, arquivou os blocos de parafina e as lâminas de todos os exames que realizou, desde o princípio, o que revelou 0 real valor de seus arquivos, salientando-sea documentação farta dos mais típicos aos mais raros casos.

$\mathrm{N}$ a ocasião de sua nova instalação, contou com a chefia do Professor Francisco Fialho, sendo seu 10 assistente 0 médico 0 nofre Ferreira de Castro e colaboradores os médicos Athayde Soares de Almeida, Bráulio Carlos Bezerra Filho, José M aria Pinto Barcelos, Ivo Ricci e Alcides da Silva Santos, além de vários patologistas de outros estados que estagiaram no serviço.

$\mathrm{N}$ a segunda metade da década de 1960, O nofre Ferreira de Castro assumiu, pela primeira vez, a C hefia do Serviço e procurou estabelecer trabalhos cooperativos com outras instituições nacionais e estrangeiras, o principal deles com o Professor Karl Lennert, da Universidade de Kiel, na Alemanha, para o estudo de linfomas. Além disso, definiu o primeiro programa regular de residência médica no Serviço.

A grande crise econômica mundial causada pelo choque do preço do petróleo marcou a década de 1970 desde o seu início, e o Brasil foi duramente atingido, gerando uma época de grandes dificuldades para investimento e mesmo o custeio dos órgãos públicos. Infelizmente, este período coincidiu com a necessidade de se reconstituir a equipe do Serviço, vez que a maioria dos médicos passara a aposentada ou demissionária. Em 1976, o staff do Serviço estava reduzido a um patologista, que exercia a chefia, e a um citopatologista.

No final de 1977, o Professor M anoel Barretto 
Netto, chefe do D epartamento de Patologia da Universidade Federal Fluminense (UFF), propôs a O nofre de Castro, também professor deste Departamento, um convênio para treinamento em Serviço em Patologia O ncológica de professores, residentes e mestrandos da UFF. 0 projeto iniciou-se em 1978 e mostrou-se muito útil para as duas instituições, pois, ao mesmo tempo em que fornecia a indispensável mão-de-obra especializada para impedir a interrupação dos diagnósticos morfológicos no Instituto $\mathrm{N}$ acional de $\mathrm{C}$ âncer, complementava $\mathrm{O}$ treinamento específico dos docentes e alunos da UFF na área da Patologia 0 ncológica. Resolvido este problema crucial $\mathrm{O}$ nofre de $\mathrm{C}$ astro pôde dedicar-se à reconstituição da equipe e melhorias no serviço.

Efetivamente este processo começou com as contratações dos patologistas Antonio Geraldo do $\mathrm{N}$ ascimento eR oberto Alfonso Arcuri, seguida por várias outros que hoje são a base da atual equipe.

N esta fase, a Residência M édica do INCA se consolidou de forma definitiva e regular e foram criados cursos de especialização em várias áreas da patologia oncológica. Em 1982 o Serviço voltava a sua plenitude com equipe plena e diversas melhorias na área física.

No meio da década de 1980, assumiu a chefia o médico Antônio $\mathrm{N}$ ascimento, que usou todo o seu talento para o ensino e liderança, apoiados na sua invulgar capacidade diagnóstica, para iniciar uma verdadeira revolução dos procedimentos relativos à rotina de Patologia Cirúrgica e Citopatologia, com profundos reflexos no funcionamento não só do IN CA, mas da Patologia em toda a cidade do Rio de Janeiro.

Antônio $\mathrm{N}$ ascimento à frente do Serviço de Anatomia Patológica impulsionou a área de ensino e formação de pessoal, e recolocou o nome do Serviço em destaque no cenário nacional, atraindo muitos patologistas de outros estados, e até mesmo de outros países, para treinar no Instituto Nacional de Câncer. Sua gestão foi interrompida pelo convite para retornar definitivamente aos Estados U nidos, onde havia feito toda a sua formação de patologista.

Antônio N ascimento foi sucedido por Roberto Arcuri, que tratou de dar continuidade à filosofia de trabal ho implantada e cuidou de melhorar as condições do ambiente de trabalho, implementando obras e incorporando equipamentos novos. Desde logo, interessou-se por implantar uma linha de trabalho conjunto com o setor de Pesquisa Básica, que cresceu a ponto de deslocá-lo para conduzir a equipe responsável pela realização deste projeto. Com isso, 0 nofre de Castro reassumiu a chefia. Em 1995, esta foi assumida por Wilhermo Torres, professor da Universidade
Federal Fluminense.

O s anos 1990 trouxeram grandes modificações para - I N C A, aumentando cada vez mais o seu papel nacional de órgão condutor da política nacional de prevenção e controle do câncer do M inistério da Saúde.

A história da Patologia viria a ser profunda e positivamente afetada por este processo nos anos a seguir.

No início daquela década, ao IN CA coube assumir 0 controle de al gumas instituições federais entre as quais estava o PITEC-RJ, do então do extinto IN AM PS, um programa voltado para o exame colpocitológico de mulheres e para a formação de citotécnicos. De todos os PITEC criados pelo Governo Federal em vários estados, apenas o do Rio de Janeiro, organizado e chefiado por $M$ ario Jaconianni, cresceu e foi o único que continuou seu trabalho de forma ininterrupta até os dias atuais. Já incorporado ao I N CA, o PITEC passou a se chamar SITEC e, após a aposentadoria do seu responsável, foi chefiado por $\mathrm{N}$ elson Cardoso de Almeida, até sua convocação para atuar no $M$ inistério da Saúde em Braślia, quando então assumiu Lucília Zardo.

O SITEC-RJ havia-se transformado no modelo de funcionamento integrado entre unidades municipais, estaduais e federais, estabelecendo níveis diferenciados de atuação desde os mais simples até o sofisticado sistema de encaminhamento em vigor no município do Rio de Janeiro, em que a emissão do resultado do exame colpocitológico já vem acompanhado deorientações para as mulheres segundo seu diagnóstico, inclusive com a marcação de próxima consulta com local de atendimento e hora definidos.

Este tem sido o principal laboratório para testes das rotinas a serem recomendadas para implantação, em todo o Brasil, dentro do Programa $\mathrm{N}$ acional de Controle do Câncer do Colo do Útero, coordenado pelo IN CA.

0 utra instituição incorporada ao Instituto foi 0 $\mathrm{H}$ ospital de $\mathrm{O}$ ncologia, no bairro de Santo Cristo, que também tinha o seu próprio Serviço de Patologia, chefiado por Jorge $\mathrm{H}$ enrique $\mathrm{G}$ omes de $\mathrm{M}$ attos. $\mathrm{O}$ mesmo aconteceu com o Hospital Luíza Gomes de Lemos, no bairro deV ila Isabel, cujo serviço de Patologia era chefiado por Lucília Zardo.

$\mathrm{N}$ a segunda metade da década de 1990 , um grande fórum de discussão sobre os rumos do IN CA elaborou um plano diretor que previa a unificação de vários serviços duplicados ou triplicados pelas incorporações já mencionadas. O Serviço de Anatomia Patológica do H ospital do C âncer I, localizado na Praça C ruz Vermelha, foi o escolhido para centralizar o processo por ser o maior e o mais complexo dos três hospitais do IN CA, vez que, desde a gestão de 0 nofre de C astro, 
já tinha implantado o laboratório de imunohistoquímica, um dos primeiros do país, e avançado bastante no ensino de pós-graduação lato sensu, iniciado processo de informatização de todas as rotinas, reformado boa parte das intalações eaumentado a equipe de forma substancial.

A partir de 1999, o processo de unificação teve início com a fusão dos serviços do $\mathrm{H}$ ospital do Câncer I e do H ospital do Câncer III (ex- H ospital Luíza Gomes de Lemos), funcionando dentro do modelo que viria a ser definitivamente implantado, testando a funcionalidade do conceito de área satélite de Patologia ligada a um serviço central, com o objetivo de homogeneizar procedimentos e aplicar melhor os recursos materiais e humanos disponíveis. D epois do estudo de algumas opções, foi decidido que a nova Patologia do IN CA seria totalmente unificada em uma nova área, contruída especialmente para este fim no Santo C risto, ao mesmo tempo em que se fariam as adaptações necessárias para o funcionamento dos núcleos hospitalares, com a presença de patologistas, técnicos e pessoal de apoio administrativo.

Em 23 de agosto de 2002, foi completado o processo deunificação dentro da nova D ivisão dePatologia- DIPAT, que incorporou os serviços de Patologia do $\mathrm{H}$ ospital do Câncer I, do H ospital do Câncer II (antigo H ospital de O ncologia), do H ospital do Câncer III e o SITEC.

Essa D ivisão hoje conta com 153 servidores diretos e mais 30 outros em tarefas complementares indispensáveis ao seu funcionamento, como informática, biblioteca, segurança, limpeza, manutenção, transporte e outros. Por ano, são examinadas 290.000 colpocitologias pela Área de Prevenção e Diagnóstico Precoce (antigo SITEC) da D ivisão, correspondente a material coletado proveniente de postos de saúde de 24 municípios do Rio de Janeiro. Também são anualmente processadas 10.000 citologias não-ginecológicas predominantemente hospitalares; cerca de 1.000 exames citológicos imediatos associados a procedimentos radiológicos invasivos e punções ambulatoriais, especialmente no Hospital do Câncer I; aproximadamente 9.000 congelações per-operatórias nos três hospitais, 100.000 lâminas de Patologia Cirúrgica e em torno de 110 necrópsias.

Foram estabelecidos os $\mathrm{N}$ úcleos $\mathrm{H}$ ospitalares de Patologia, em cada um dos hospitais, sob a responsabilidade dos patologistas Ana Lúcia Amaral Eisenberg ( $\mathrm{HC} \mathrm{I}$ ), Jorge $\mathrm{H}$ enrique Gomes de $\mathrm{M}$ attos
(HC II) e Lídia M agalhães (HC III). As atividades do antigo SITEC foram assumidas pela Área de Prevenção e Diagnóstico precoce da DIPAT, sob a coordenação da citopatologista Lucília Zardo.

A DIPAT mantém o programa de Residência M édica em Patologia, com a entrada de três novos residentes por ano; do Curso de Formação de Citotécnicos, com trinta vagas anuais, e, em 2003, inicia o de Formação de $\mathrm{H}$ istotécnicos, com cinco vagas. A D ivisão também atua na consultoria para os assuntos relacionados com a especialidade solicitada pelos demais setores do INCA responsáveis pela execução dos programas nacionais de prevenção e controle do câncer no país, promovendo a aproximação e a parceria com as sociedades da especialidade (Sociedade Brasileira de Patologia, Sociedade Brasileira de Citopatologia e Associação Brasileira de Laboratórios de Anatomia Patológica e Citopatologia) para a elaboração destes programas.

O s chefes acima mencionados sempre contaram com a inestimável colaboração de numerosos servidores que contribuíram de forma significativa para 0 funcionamento e crescimento da Patologia nos quatro serviços do INCA, entre técnicos, médicos, pessoal administrativo, alguns inclusive já falecidos. Só por receio da omissão injusta, que freqüentemente ocorre nestas situações, é que eles não estão aqui relacionados.

A evolução da Patologia no I N C A émaisum exemplo não só da progressão estrutural eoperacional do Instituto, ao longo de suas seis décadas de existência, como do avanço técnico e gerencial que a unificação de serviços vem significando.

Por isso, a história da Patologia, mais do que a história de seções, serviços e equipes, é a história do próprio Instituto Nacional de Câncer. $\mathrm{E}$ dos diretores que o conduziram e o conduz: M ário Kröeff (1938/ 1941), Alberto Lima de M oraes Coutinho (1941/1954), Luiz Carlos de Oliveira Júnior (1954/1956), Antônio Pinto Vieira (1956/1962), M oacyr Alves dos Santos Silva (1962/1963 e 1972/1974), Francisco Fialho (1963/1967 e 1969/1970), Jorge Sampaio de M arsillac M otta (1967/ 1969), U go de C astro Pinheiro Guimarães (1970/1972), Adayr Eiras de Araújo (1974/1978), João Carlos C abral (1978), Wolfgang George Lamprecht (1978/1979), H iram Silveira Lucas (1979/1980), Ary Frauzino Pereira (1980/1985), G eraldo M attos deSá (1985/1986), W alter Roriz de Carvalho (1986/1990), M arcos Fernando de O liveira M oraes (1990/1998) e Jacob K ligerman (1998/ 2003). 